IRA-International Journal of Education \& Multidisciplinary Studies

ISSN 2455-2526; Vol.14, Issue 01 (January, 2019)

Pg. no. 5-13.

Institute of Research Advances

$D A \begin{gathered}\text { Institute of } \\ \text { Research } \\ \text { Advances }\end{gathered}$

http://research-advances.org/index.php/IJEMS

\title{
On the Translation of "Drinking Alone under the Moon" Based on the Harmony-Guided Criteria for Poetry Translation
}

\author{
Yan Qian ${ }^{1}$, Wang Feng ${ }^{2 \#}$ \\ \# corresponding author. \\ Type of Work: Peer Reviewed \\ DOl: http://dx.doi.org/10.21013/jems.v14.n1.p2
}

School of Foreign Studies, Yangtze University, Hubei, 434023 PRC China.

\section{How to cite this paper:}

Yan, Q., Wang, F. (2019). On the Translation of "Drinking Alone under the Moon" Based on the Harmony-Guided Criteria for Poetry Translation. IRA International Journal of Education and Multidisciplinary Studies (ISSN 2455-2526), 14(1), 5-13.doi: http://dx.doi.org/10.21013/jems.v14.n1.p2

(C) Institute of Research Advances.

This work is licensed under a Creative Commons Attribution-Non Commercial 4.0 International License subject to a proper citation to the publication source of the work.

Disclaimer: The scholarly papers as reviewed and published by the Institute of Research Advances (IRA) are the views and opinions of their respective authors and are not the views or opinions of the IRA. The IRA disclaims of any harm or loss caused due to the published content to any party.

Institute of Research Advances is an institutional publisher member of Publishers International Linking Association Inc. (PILA-CrossRef), USA. The institute is an institutional signatory to the Budapest Open Access Initiative, Hungary advocating the open access of scientific and scholarly knowledge. The Institute is a registered content provider under Open Access Initiative Protocol for Metadata Harvesting (OAI-PMH).

The journal is indexed \& included in WorldCat Discovery Service (USA), CrossRef Metadata Search (USA), WorldCat (USA), OCLC (USA), Open J-Gate (India), EZB (Germany) Scilit (Switzerland), Airiti (China), Bielefeld Academic Search Engine (BASE) of Bielefeld University, Germany, PKP Index of Simon Fraser University, Canada.

${ }^{1}$ Yan Qian is a postgraduate of QX181 in the School of Foreign Studies, Yangtze University.

${ }^{2}$ Wang Feng (corresponding author) is an Associate Professor in the School of Foreign Studies, Yangtze University. His research interests include translation studies, intercultural communication, and interpreting studies. 


\section{ABSTRACT}

Under Dr Wang Feng's Harmony-Guided Criteria for poetry translation, this paper attempts to conduct an analysis on four English versions of Li Bai's "Drinking Alone under the Moon" at three levels, exploring the gains and losses of each version and verifying the guiding role of the Harmony-Guided Criteria in poetry translation. It aims to provide some inspiration and reference for poetry translators and promote the dissemination of classic Chinese culture at the same time.

Keywords: Harmony-Guided Criteria; poetry translation; Li Bai; "Drinking Alone under the Moon".

\section{INTRODUCTION}

The Tang poetry is the peak of Chinese poetry and an important heritage of Chinese literature. Li Bai's works characterized by romanticism are a rare treasure in classic Chinese poetry. "Drinking Alone under the Moon", one of his excellent works, has long been praised as a masterpiece of expressing loneliness and has always drawn the attention of researchers at home and abroad. A number of scholars have utilized different translation theories to study its English versions (Hu Xiaoying, 2011; Wei Wei and Wei Jingjing, 2012). They applied the Skopos Theory and Relevance Theory to their analyses respectively. In the paper, the author tries to analyze four English versions of the same Tang poem from a relatively new angle by adopting Dr Wang Feng's Harmony-Guided Criteria to investigate its guiding significance for translating Chinese poetry into English.

\section{The Harmony-Guided Criteria for Poetry Translation}

Dr Wang Feng (2011) put forward the Harmony-Guided Criteria in order to provide guidelines and solutions for poetry translation. At the macro level, he analyzed the disharmonies between Chinese and English poetry, regarding "Harmony" as the macro standard of poetry translation; at the middle level, he integrated varied criteria for the translation of Chinese poetry and came up with "Similarity of Style, Sense and Poetic Realm"; at the micro level, "Eight Beauties" were proposed on the basis of specific theories to guide the practice of poetry translation.

\subsection{Macro Level: Harmony}

Dr Wang Feng (2015) proposed six disharmonies between Chinese and English poetry. In order to resolve these disharmonies, translators must view "Harmony" as the macro criterion of poetry translation.

\subsection{Middle Level: Similarity of Style, Sense and Poetic Realm}

It is necessary and essential to put forward "Similarity of Style, Sense and Poetic Realm" at the middle level, because "Harmony" can only instruct translation practice and poetry translation criticism at the macro level. "Similarity of Style" indicates that the style of the translated version should be similar to that of the original poem; "Similarity of Sense" means that the translated version must convey the meanings of the original poem faithfully. "Similarity of poetic Realm" refers that the comprehensive effect of poetic realm produced by the translated version in readers of the target language should resemble that generated by the original poem in readers of the source language.

\subsection{Micro Level: Eight Beauties}

On the foundation of Xu Yuanchong's Three-Beauty Theory (1987), Lin Yutang's Five-Beauty Theory (1995), Gu Zhengkun's Poetry Appreciation Theory (1998) and other theories of poetry translation, Dr. Wang Feng has come up with "Eight Beauties" at the micro level to direct the practice and criticism of poetry translation. 


\section{2. "Drinking Alone under the Moon" and its English Versions}

\subsection{An Introduction to "Drinking Alone under the Moon"}

"Drinking Alone under the Moon" was written by Li Bai, one of the best poets of the Tang Dynasty. In the beginning, the poem described a dismal scene in which the poet drank alone among flowers and under the moon. Through fantastic imagination, the poet then presented a seemingly festive scene where the poet sang and danced with the companion of the shadow and the moon. The poet transformed inanimate natural things into living and affectionate people. Drinking, singing and dancing with them, he even expected to make close friends with them, especially the moon, forever. The whole poem conveyed the poet's loneliness and depression caused by unrecognized talent, but it also expressed his unconstrained character and open-minded feelings. In the poem, sadness was hidden behind the shared fun of the three, and joy was created to contrast the emptiness, which demonstrated a strong artistic effect. The original Chinese poem is as follows:
《月下独酌》（其一）
花间一壸酒，独酌无相亲。
举杯邀明月，对影成三人。
月既不解饮, 影徒随我身,
暂伴月将影, 行乐须及春。
我歌月徘徊, 我舞影零乱。
醒时相交欢，醉后各分散。
永结无情游，相期䢬云汉。

\subsection{Four English Versions}

There are four English versions selected by the authors to make comparison and contrast, all of which are translated by famous translators.

\section{Version 1: Last Words}

An arbor of flowers and a kettle of wine:

Alas! In the bowers no companion is mine.

Then the moon sheds her rays on my goblet and me,

And my shadow betrays we 're a party of three!

Thou' the moon cannot swallow her share of the grog,

And my shadow must follow wherever I jog.

Yet their friendship I'll borrow and gaily carouse,

And laugh away sorrow while springtime allows.

See the moon-how she glances response to my song;

See my shadow-it dances so lightly along!

While sober I feel, you are both my good friends;

While drunken I reel, our companionship ends.

But we'll soon have a greeting without a goodbye,

At our next merry meeting away in the sky.

\section{$\underline{\text { TR. Herbert Allen. Giles }}$}

\section{Version 2: Drinking Alone by Moonlight}

A cup of wine, under the flowering trees;

I drink alone, for no friend is near.

Raising my cup I beckon the bright moon; 
For he, with my shadow, will make three men.

The moon, alas, is no drinker of wine;

Listless, my shadow creeps about at my side.

Yet with the moon as friend and the shadow as slave,

I must make merry before the Spring is spent.

To the songs I sing the moon flickers her beams;

In the dance I weave my shadow tangles and breaks.

While we were sober, three shared the fun;

Now we are drunk, each goes his way.

May we long share our odd, inanimate feast,

And meet at last on the Cloudy River of the sky.

$\underline{\text { TR. Arthur Waley }}$

\section{Version 3: We Three}

One pot of wine amid the flowers,

Alone I pour, and none with me.

The cup I lift; the Moon invite,

Who with my shadow makes us three.

The moon then drinks without a pause;

The shadow does what I begin.

The shadow, Moon and I in fere,

Rejoice until the spring comes in.

I sing: and wavers time the moon.

I dance: the shadow antics too.

Our joys we share while sobers still.

When drunk, we part and bid adieu.

Of loveless outing this the pact,

Which we all swear to keep for aye.

Till next time that we meet shall be,

Beside yon distant milky way.

\section{TR. W.J.B. Fletcher}

\section{Version 4: Drinking Alone under the Moon}

Amid the flowers, from a pot of wine,

I drink alone beneath the bright moonshine.

I raise my cup to invite the Moon who blends;

Her light with my Shadow and we're three friends.

The Moon does not know how to drink her share;

In vain my Shadow follows me here and there.

Together with them for the time I stay,

And make merry before spring's spent away.

I sing and the Moon lingers to hear my song;

My Shadow's a mess while I dance along. 
Sober, we three remain cheerful and gay;

Drunken, we part and each may go his way.

Our friendship will outshine all earthly love;

Next time we'll meet beyond the stars above.

TR. Xu Yuanchong

\section{Analysis of the English Versions Based on the Harmony-Guided Criteria for Poetry Translation}

The authors will compare and analyze the four English versions mentioned above at macro, middle and micro levels. And the first author will put forward her own translated version in the end.

\subsection{Analysis at the Macro Level}

Translation between two different languages is actually a cross-cultural communication. The differences in language and culture brought about varied disputes and even confrontations in translation. As far as the characteristics of Chinese and English poetry are concerned, there are mainly six disharmonies. Chinese poetry put particular emphasis on art, lyricism, change of tone, parataxis, connotation and integrity, while English poetry attaches more importance to science, narration, stress in syllables, hypotaxis, hyperbole, enjambment. When translating Chinese poetry into English, translators should consider the characteristics of Chinese and English poetry comprehensively to reproduce the original poem as much as possible for English readers.

In the original Chinese poem, the subjects of several lines are omitted and there are no conjunctions between words. Grammar and logic are just implied in them. But the four translators have added corresponding subjects when translating the poem into English, which can be explained by the fact that English poetry relies on correct grammatical structures to express meanings. Consequently, the subjects and grammatical conjunctions cannot be omitted at will in English versions. For instance, when translating “独酌无相亲”, the four translators all added a subject "I" to it, which not only accorded with the characteristics of English poetry but delivered the implied meanings of the original poem.

Actually, the translated version may lose the original poetic conception if too much emphasis is laid on the hypotaxis of English poetry, and it would result in reading barriers to English readers if it overemphasizes the parataxis of Chinese poetry. Therefore, only when translators adhere to the "Harmony" criterion at the macro level, can they achieve a better balance between the value of the original poems and the features of the target language.

\subsection{Analysis at the Middle Level}

In the first place, "Similarity of Style" will be discussed. The poem portrayed a sight of drinking alone by the moonlight, revealing the poet's loneliness and sadness from political frustration and indicating his broad-mindedness. The literal meaning of "独" in the title of the original poem is "without a companion". The word implies that the poet was lonely and he could not find any close friend to relieve his inner frustration. The second version and the fourth version both communicated the meaning of the original title accurately and concisely by using the word "alone", which is easy for English readers to comprehend the poet's sense of loneliness. In contrast, "Last Words" of the first version may deliver an irrelevant meaning that the poem was the last work of Li Bai before his death or he was in despair to English readers. It is obvious that the translation is quite different from the style of the original poem. Moreover, "We Three" of the third version is more inconsistent with the lonely style and it even doesn't keep to the core content of the original poem. Another example is the translation of “花间一壶酒, 独酌无相亲”. Generally speaking, the third and the fourth translations are reasonable. But the first version fails to express the meaning of “花间” and it does not 
translate the word “酌”. Besides, “arbor" is a place that tends to appear in western houses according to dictionaries, so the word conflicts with the lifestyle of ancient Chinese people. It can be inferred from Li Bai's vigorous and unconstrained style that the scene described in the poem is more likely to be an outdoor and open place. So it is more appropriate to understand “花间” as “among outdoor flowers”. The third version translates it into "under the flowering trees", in which the translator completely misunderstands the meaning of “花间” and the expression itself will bring about ambiguity.

In the second place, "Similarity of Sense" will be analyzed. Meaning is important Chinese poetry, so it should be conveyed and reproduced as much as possible. The translation of “举杯邀明月，对影成三人” is taken as an example. The first version misses the translation of the keyword “邀” and misemployed the word "betray" that means "my shadow reveals we are three". Likewise, the second version mistranslated “一壶酒” into "a cup of wine", not faithful to its original meaning as a cup is much smaller than a pot in the original. When translating “月既不解饮” , the third translator has totally distorted the original poem. In the third version, the moon becomes a drinker who can drink a lot. It evidently runs counter to the original meaning that the moon can't drink and doesn't know the pleasure of drinking. In the meanwhile, the third version mistranslates “及春” into “until the spring come in”. In the original poem, “及春” means “seizing the great moments before spring ends" instead of "when spring comes". The last example is the translation of “无情游” which means sincere friendship in compliance with inner feelings and beyond the constraint of manner. The first version directly avoids translating it. The second one reveals that the translator doesn't grasp its true implication, so does the literal translation "loveless" of the third one. The author believes that "outshine all earthly love" in the fourth one accurately delivers the connotation of “无情游”.

In the third place, "Similarity of Poetic Realm" will be brought into the evaluation. It is no exaggeration to say that the translated version will lose the soul of the original poem if it does harm to the original poetic realm. Thus, it is essential for translated versions to reproduce the poetic realm of the original ones. In the poem, "我 歌月徘徊, 我舞影零乱” shows the poet's best state of drinking-half sober and half-drunken. “徘徊” and “零乱” are two crucial words in creating the poetic realm, to which much attention should be paid during translating. The first three versions fail to reproduce the original poetic realm - "when the poet sings, the moon lingers on and listens to his song absorbedly". By comparison, the word "linger" used in the fourth version is vivid and succeeds in creating a similar poetic realm to that of the original one. Although the translation of "我 舞影零乱” in the fourth version is faithful, it loses part of the original poetic realm due to the word "mess". The first version just highlights that "my shadow dances along with me", but it doesn't translate the word “零乱”. Nevertheless, the word "tangle" used in the second version is similar to "tango" in pronunciation. It not only expresses the meaning of “零乱”, but depicts a romantic scene where "the shadow and the poet are dancing together". A strong literariness and parallel poetic realm come into being at the same time in the second version.

\subsection{Analysis at the Micro Level}

\section{a) Beauty of Form}

The "Beauty of Form" refers to the external form of a poem, like the number of lines, arrangement, length, indentation and so on. The original poem is a five-character verse and contains fourteen lines. Both of the first two versions don't change the number of lines but each line is different in length, particularly in the second one, each line varying from eight syllables to thirteen syllables. The third version contains sixteen lines in total, with eight syllables in each line except the first. Apart from the fourth line, the other thirteen lines in the fourth version each have ten syllables. In general, the fourth version embodies the beauty of form and the formal beauty in the other three versions are lost more or less.

b) Beauty of Musicality 
The "Beauty of Musicality" refers to the aesthetic perception formed by tone, rhythm, rules of rhyming and other factors in a poem. In the first version, the rhyme is changed every two lines and the translator uses diphthongs, long vowels and consonants alternately to highlight the change of rhythm. There is no regular rhythm in the second version. The rhythm of the third version is almost iambic tetrameter with a rhyming scheme of $a b c b$,defe,ghih,jkbk. And the last version is nearly iambic pentameter and its rhyme mode is aabbccddeeddff. Except for the second one, the other three versions present a strong sense of music in translation.

c) Beauty of Image

The "Beauty of Image" refers to the visual beauty of poetry shaped by vivid and sensible images or perceptual elements of image groups in reality or imagination. In this poem, "shadow" and "moon" are very important images. However, in the second version, “影徒随我身” is translated into “Listless, my shadow creeps about at my side”. But it can be judged from the following “影零乱” that the shadow can't be a tired or listless image. In addition, the translator adds an image "slave" that is not present in the original poem at all. It is evident that the poet regards "shadow" and "moon" as his close friends in the poem. So the word "must" in the first version also breaches the image of "shadow" in the original poem. The translation of the third one is accurate in expressing meanings but the beauty of the image is almost lost here. Comparatively speaking, the image of shadow is well reproduced in the last one which uses the phrase "in vain".

d) Beauty of Emotion

“醒时相交欢” renders a joyful atmosphere of the poet making merry with the shadow and the moon, behind which lies the poet's inner depression. It aims to stress the lonely image of the poet in reality. Although the first version is faithful to the original meanings when translating “醒时相交欢, 醉后各分散” , its choice of words and expressions are relatively flat. It is hard for English readers to understand the poet's complex feelings of loneliness and broad-mindedness. However, in the fourth version, the translator puts "sober" and "drunken" at the beginning of the sentences respectively. Moreover, the word "cheerful" in the last sentence contrasts with the word "part" in the next one distinctively. Its expression conveys the complex feelings of the poet accurately and concisely to English readers. So the fourth version can best embody the Beauty of Emotion.

e) Beauty of Suggestiveness

The beauty of suggestiveness has long been considered as an important principle for poetry composition and it mainly refers to implicit expressions in poetry. The beauty of suggestiveness can be achieved by various means like metaphors, puns, symbolism, etc. Besides, polishing words or sentences can also realize it. For example, the fourth version translated “遥” into a preposition "beyond" instead of an adjective like "high" or "lofty" literally. The polished word "beyond" conveys the meanings of "far" and "high", which enriches the poetic realm and thereby enhance the implicit flavour. As a matter of fact, the beauty of suggestiveness is almost non-existent in the fourth English version.

f) Beauty of Diction

The "Beauty of Diction" requires that translators should respect the hard work of authors and select the most appropriate words to convey the messages of the original poems. For instance, the words "jog" and "borrow" in the first version reflect the Beauty of Diction. "Jog" here means "moving unsteadily". The word is used properly because the poet will inevitably walk unsteadily after drinking. The other word "borrow" implies that the shadow and the moon just lend their companion to the poet for a while. It makes the lonely and helpless mood of the poet more salient. Other similar examples include "tangle" in the second version and "outshine" in the last one.

g) Beauty of Allusion 
The "Beauty of Allusion" refers to the aesthetic feelings produced in readers' mind by using allusions in poems. In the poem, the word “无情” actually derives from an allusion of 《庄子・德充符》 in which Huizi and Zhuangzi had a discussion about “无情” and “有情”. But the four English versions don’t provide annotation for readers' reference, all of which don't manifest the Beauty of Allusion. In the author's view, it is necessary to note the allusion and offer an explanation of the word “无情”.

h) Beauty of Gestalt

Seven specific beauties discussed above are unlikely to cover all the beauties in different poems or the unique beauty in a certain poem. The beauties in poetry may differ from one to another. Thus, poetry translators need to pay a different degree of attention to each certain beauty in accordance with the features of an original poem. The "Beauty of Gestalt" refers to the whole of the unmentioned beauty of number, visual transformation, etc., except for the seven aforementioned specific beauties. It's worth noting that the beauties are not isolated and they should be reproduced as a whole in a translated version.

Under the instruction of the Harmony-Guided Criteria for poetry translation discussed above, the first author would like to present her translation.

\section{Drinking Alone Under the Moon}

\section{Li Bai, translated by Yan Qian}

Among the flowers is a pot of wine;

I drink alone with no partners of mine.

To beckon the moon I raise my cup;

We are three when my shadow shows up.

The moon does not know the joy of drinking;

My shadow follows me wherever I'm walking.

For a while, they company me like friends;

I shall make merry before spring ends.

When I sing, the moon wanders with my song;

My shadow tangles as I dance along.

Sober, we share pleasure all together;

Drunken, we will part and go away.

May we be sincere friends forever, (1)

And meet again beyond the sky someday.

(1)The word “无情” derives from an allusion of 《庄子・德充符》 in which Huizi and Zhuangzi had a discussion about “无情” and “有情” and it doesn’t mean “loveless”.“无情游” means sincere friendship in compliance with inner feelings and beyond the constraint of manner.

\section{Conclusion}

After comparing and contrasting the four English versions of "Drinking Alone under the Moon" under the Harmony-Guided Criteria for poetry translation, the authors listed the advantages and disadvantages of each translated version. In general, the fourth English version translated by $\mathrm{Xu}$ Yuanchong prevails over the other versions particularly in the beauty of form, the beauty of musicality and the beauty of emotion. Its translation basically meets the macro and middle criteria, while the beauty of diction and the beauty of allusion at the micro level need to be improved.

It can be concluded that the "Harmony-Guided Criteria" for poetry translation put forward by Dr Wang Feng plays a positive role in the English translation of classical Chinese poetry. When translating a poem, translators should follow the criterion of "Harmony" at the macro level to cope with disharmonies between Chinese and English poetry, comply with the criterion of "Similarity of Style, Sense and Poetic Realm" at the 
middle level to deliver the meanings of the original faithfully, and lay emphasis on the representation of the beauties at the micro level. Under the guidance of the "Harmony-Guided Criteria" for poetry translation, an English version of higher quality can be produced, which will make a contribution to the dissemination of classical Chinese literature and culture into foreign countries.

\section{References}

[1]. Fletcher, W.J.B. More Gems of Chinese Poetry Translated into English Verse [M]. Shanghai: The Commercial Press, 1919.

[2]. Giles, Herbert Allen.Chinese Poetry in English Verse [M]. Shanghai: Kelly \& Walsh, 1898.

[3]. Gu, Zhengkun. China and West: Comparative Poetics and Translatology. Beijing [M]: Tsinghua University Press, 1998.

[4]. Hu, Xiaoying. On the Translation of Tang Poetry from the Perspective of Skopos Theory-Taking "Drinking Alone under the Moon" as an Example [J]. Journal of Southeast University for Nationalities, 2011.

[5]. Lin, Yutang. On Translation[A].The Complete Works of Lin Yutang [C]. Changchun: Northeast Normal University Press, 1995.

[6]. Waley, Arthur. The Poetry and Career of Li Po[M]. London: Allen \& Unwin, 1950.

[7]. Wang, Feng. A Comprehensive Study on the English Translation of Classic Tang Poetry [M]. Beijing: China Social Sciences Press, 2015.

[8]. Wang, Feng. On the Influence of Chinese Poetry upon American Poetry [J]. Seeker, 2011(3).

[9]. Wang, Feng \& Ma Yan. A Critical Anthology of Tang Poems and their English Translation [M]. Xi'an: Shanxi People's Publishing Press, 2011.

[10]. Wei Wei and Wei Jingjing. On the Representation of Context and Intention in the English Versions of "Drinking Alone under the Moon" under the Relevance Theory[J]. Overseas English, 2012.

[11].Xu, Yuanchong. On "Beauty in Sense, Sound and Form" [J].Journal of Shenzhen University, 1987.

[12].Xu, Yuanchong. An Anthology of Classical Chinese Poetry[M]. Beijing: New World Press, 1994. 